Cite this: Energy Environ. Sci., 2014, 7, 2670

Received 25th February 2014 Accepted 28th April 2014

DOI: $10.1039 / c 4 e e 00602 j$

www.rsc.org/ees

\section{Evolution of disposable bamboo chopsticks into uniform carbon fibers: a smart strategy to fabricate sustainable anodes for $\mathrm{Li}$-ion batteries $\dagger$}

\author{
Jian Jiang, t’ $^{\mathrm{a}}$ Jianhui Zhu, + $^{\mathrm{a}}$ Wei Ai, ${ }^{\mathrm{a}}$ Zhanxi Fan, ${ }^{\mathrm{b}}$ Xiaonan Shen, ${ }^{\mathrm{a}}$ Chenji Zou, ${ }^{\mathrm{a}}$ \\ Jinping Liu, ${ }^{d}$ Hua Zhang ${ }^{b}$ and Ting Yu*ac
}

Future development of mini consumer electronics or large electric vehicles/power grids requires Li-ion batteries (LIBs) with not only an outstanding energy-storage performance but also a minimum cost, and the foremost sustainability. Herein, we put forward a smart strategy to convert used disposable bamboo chopsticks into uniform carbon fibers for anodes of LIBs. Bamboo chopsticks waste is recycled and simply treated by a controllable hydrothermal process performed in alkaline solutions, wherein abundant natural cellulose fibers in bamboo in situ get separated and dispersed spontaneously. After carbonization, the evolved carbon fibers exhibit superior anodic performance to the bulky bamboo carbons counterpart, and competitive electrochemical behavior and cost with commercial graphite. The performance of carbon fibers can be further upgraded by growing nanostructured metal oxides (like $\mathrm{MnO}_{2}$ ) firmly on each fiber scaffold to form a synergetic core-shell electrode architecture. A high reversible capacity of $\sim 710 \mathrm{~mA} \mathrm{~h} \mathrm{~g}^{-1}$ is maintained without decay up to 300 cycles. Our strategy presents a scalable route to transform chopsticks waste into carbon fibers, offering a very promising way to make sustainable anodes for LIBs and economical multi-functional carbon-based hybrids available for other practical applications.

\begin{abstract}
Broader context
Li-ion batteries (LIBs) nowadays play a dominant role on the progress of HEVs/EVs industry. However, despite the ceaseless development of electrode materials selection/manufacturing, current LIBs still show little promise in competing with the traditional gasoline in terms of price, energy, convenience and safety. Besides, the excepted huge exploitation on graphite driven by future demands will eventually one day lead to the depletion of natural graphitic resources. In a long-term perspective, LIBs therefore require to not only possess outstanding energy-storage capability but also be lower-cost and foremost sustainable. We herein propose a smart strategy to convert the used bamboo chopsticks into uniform carbon fibers for a sustainable anode of LIBs. Abundant natural fibers in chopsticks waste are readily separated and dispersed after a simple hydrothermal treatment. The derived carbon fibers exhibit superior anodic performance as compared to the bulky counterparts, and competitive electrochemical behavior and cost with commercial graphite. Moreover, their performance can be further upgraded by integrating nanostructured metal oxides onto each fiber. Our success in the evolution of carbon fibers from chopsticks waste may provide a costeffective and sustainable platform for developing advanced carbon-based materials for practical use, not merely in LIBs but also in a wide spectrum of fields.
\end{abstract}

${ }^{a}$ Division of Physics and Applied Physics, School of Physical and Mathematical Sciences, Nanyang Technological University, 637371, Singapore. E-mail: YuTing@ ntu.edu.sg; Fax: +65 6795 7981; Tel: +6563162962

${ }^{b}$ School of Materials Science and Engineering, Nanyang Technological University, 639798, Singapore

${ }^{c}$ Graphene Research Centre, National University of Singapore, 117546, Singapore

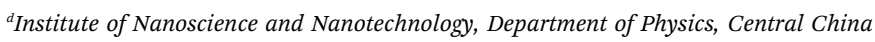
Normal University, Wuhan, 430079, Hubei, P. R. China

$\dagger$ Electronic supplementary information (ESI) available: SEM images of intermediate products during the fiber-extraction process; TEM image of a single carbon fiber; optical and SEM images of samples treated in different atmospheres; XRD pattern and TEM image of $\mathrm{C} / \mathrm{MnO}_{2} \mathrm{NWs} /$ carbon fibers. See DOI: $10.1039 / \mathrm{c} 4 \mathrm{ee} 00602 \mathrm{j}$

$\$$ Jiang Jian and Zhu Jianhui contributed equally to this work.

\section{Introduction}

The ever-increasing market penetration of hybrid electric or allelectric vehicles (HEVs or EVs) requires not only a continual improvement of the battery performance (particularly on fast charges output/storage) but also minimization of the battery cost as much as possible. Li-ion batteries (LIBs) based on the classic electrochemical system of carbonaceous anode and $\mathrm{Li}$ salts cathode (e.g., layered $\mathrm{Li}_{1-x} \mathrm{MO}_{2}$, olivine $\mathrm{LiMPO}_{4}$ and spinel $\mathrm{Li}_{1-x} \mathrm{M}_{2} \mathrm{O}_{4}$, wherein $\mathrm{M}$ represents the transition metal) are superior to nickel-metal hydride batteries ( $\mathrm{Ni}-\mathrm{MH}$ ) or ambienttemperature fuel cells on the market. ${ }^{1-3}$ They play a predominant role in the progress of HEVs/EVs industry owing to their attributes of high energy density, good rate performance, reliable stability and long lifespan. ${ }^{2}$ Despite the ceaseless 
development of LIBs technology on electrode materials selection/manufacturing, the purchase cost of HEVs/EVs (mainly spent on LIBs units and related accessories) is yet far higher than that of the mainstream gasoline-powered automobiles. Up to date, the current LIBs still show little promise of offering safe and sufficient capacity, with acceptable lifetime, good convenience and affordable price to compete with traditional fossil fuels. ${ }^{4}$ In addition, the majority of commercially used anodic graphite stems from mineral deposits. Similar to the petroleum case in history, the prospective huge exploitation on graphite driven by future demands in EVs and large electricity grids would one day lead to the depletion of graphitic resources. The successful and large-scale commercial popularization of HEVs/ EVs, in a longer-term perspective, ought to rely on the advent of renewable, environmentally benign and cheaper electrode materials that still have a satisfactory electrochemical performance, preferably close to an infinite abundance in nature. ${ }^{5}$

The use of chopsticks brings about the mysterious verve of East Asia's catering culture but inevitably results in negative environmental impact and enormous waste of precious forest resources. Only in Japan, humans stupendously consume around a total of $\sim 24$ billion pairs of disposable chopsticks per year (adding up to millions of cubic meters of timber or fully grown bamboo trees). ${ }^{6}$ This giant consumption gives rise to a great many issues, in which the overriding concern is how to appropriately deal with the vast of discarded chopsticks garbage. Current handling approaches are still the conventional ones realized by either direct combustion of these wastes or sanitary landfills for biodegradation. Even though treatments in such ways are rather simple and convenient, they are virtually "low-level" and not rational, causing extra air/dust pollution and, more importantly, making little use of these valuable and economic natural resources. How humans process the large amount of disposable chopsticks waste into commercially available products through general, high-efficiency and costeffective approaches is quite desirable but still needs serious reconsidering.

We herein put forward a scalable and smart strategy to convert disposable bamboo chopsticks waste into uniform carbon fibers for LIBs application. The recycled bamboo chopsticks only undergo a simple and controllable hydrothermal (delignification) treatment conducted in alkaline solutions, in which plenty of cellulose fibers in bamboo are in situ separated and dispersed spontaneously. Both the reaction time and alkali concentration are verified as significant parameters to adjust the overall fiber-separation process. Extracted natural fibers are further evolved into graphitic carbon fibers after a carbonization treatment. When tested as anode for LIBs, the chopsticksderived carbon fibers can exhibit competitive anodic performance with practical graphitic materials, and much better electrochemical behavior than unseparated bamboo carbon in terms of specific energy and rate capability. We also find the anodic performance of carbon fibers can be markedly upgraded by integrating nanostructured metal oxides (e.g., $\left.\mathrm{MnO}_{2}\right)$ onto each carbon fiber. Thanks to the three-dimensional (3D) functionalized core-shell constructions, the hybrid products of $\mathrm{C} / \mathrm{MnO}_{2} \quad \mathrm{NWs} /$ carbon fibers have been demonstrated as excellent anode materials for LIBs, with good cyclic performance (maintaining $\sim 710 \mathrm{~mA} \mathrm{~h} \mathrm{~g}^{-1}$ without decay up to 300 cycles) and outstanding rate capability. To our knowledge, their comprehensive anodic performance is among the best reported to date for the hybrid systems of $\mathrm{MnO}_{2}$ @carbon matrix. Our success in the evolution of carbon fibers from chopsticks waste may not only open up the possibility of manufacturing sustainable high-performance anode materials for LIBs, but also set up an economical platform for preparing advanced hierarchical carbon-based hybrid materials that might be available in a large spectrum of practical applications.

\section{Experimental}

\subsection{Synthesis of carbon fibers}

The disposable bamboo chopsticks were used as raw materials and recycled from the canteens of Nanyang Technological University (NTU). The cleaned bamboo chopsticks were initially processed into bamboo shavings (length: $\sim 1.4 \mathrm{~cm}$; width: $\sim 0.2$ $\mathrm{cm}$; thickness: $\sim 0.06 \mathrm{~cm}$ ) using a penknife. Within the underlying hydrothermal treatment, $1 \mathrm{~g}$ of bamboo shavings were put into a Teflon-lined stainless steel autoclave wherein a $70 \mathrm{~mL}$ of homogeneous $3 \mathrm{M} \mathrm{KOH}$ solution was contained. Then, the autoclave was sealed and placed still in an electric oven at a temperature of $150{ }^{\circ} \mathrm{C}$ for $6 \mathrm{~h}$. When cooled down to room temperature naturally, the samples were fetched out, collected by vacuum filtration with common filter paper, washed by ultrasonication in $150 \mathrm{~mL}$ distilled water just for one time and dried at $60{ }^{\circ} \mathrm{C}$ in an electric oven. Next, the cotton-like products were calcined at $800{ }^{\circ} \mathrm{C}$ under the protection of Ar flow (flow rate: $80 \mathrm{ppm}$ ) for $2 \mathrm{~h}$, allowing for adequate carbonization of the bamboo fibers into carbon fibers. Last, the evolved carbon fibers are washed with $0.1 \mathrm{M} \mathrm{HCl}$ to remove the residual $\mathrm{KOH}$ and dried at $60{ }^{\circ} \mathrm{C}$ for $12 \mathrm{~h}$.

\subsection{Synthesis of $\mathrm{C} / \mathrm{MnO}_{2} \mathrm{NWs} /$ carbon fibers}

The hybrid of $\mathrm{C} / \mathrm{MnO}_{2}$ @carbon fibers was prepared via simple hydrothermal treatment using carbon fibers as the raw materials. In details, a glass slide with $0.2 \mathrm{~g}$ of "cotton-like" carbon fibers fixed on, was put into a $100 \mathrm{~mL}$ Teflon-lined stainless steel autoclave containing $50 \mathrm{~mL}$ of $0.04 \mathrm{M} \mathrm{KMnO}_{4}$ solution. The autoclave was then sealed and kept in an electric oven at $150 \pm 0.1^{\circ} \mathrm{C}$ for $6 \mathrm{~h}$. Next, the hybrid samples were fetched from the glass slide and cleaned by ultrasonication treatment for a few seconds to remove $\mathrm{MnO}_{2}$ nanoparticle debris. After that, the formed intermediates were soaked into $50 \mathrm{~mL}$ of $10 \mathrm{mmol}$ glucose solution and kept still at $60 \pm 0.1{ }^{\circ} \mathrm{C}$ for $12 \mathrm{~h}$. Last, the samples were taken out, dried in air and calcined at $550{ }^{\circ} \mathrm{C}$ in $\mathrm{Ar}$ flow $(80 \mathrm{sccm})$ for $1 \mathrm{~h}$.

\subsection{Material characterization}

The crystalline structure and morphology of carbon fibers were characterized using a transmission electron microscope (highresolution TEM/TEM, JEM 2100F) and a field-emission scanning electron microscope (FESEM, JEOL JSM-6700F). An X-ray powder diffraction (XRD) pattern was recorded by a Bruker D8 
Advance diffractometer with $\mathrm{Cu}-\mathrm{K} \alpha$ radiation $(\lambda=0.15418 \mathrm{~nm})$. The mass of the electrode materials was precisely measured on a microbalance (A\&D Company N92, Japan) with an accuracy of $0.01 \mathrm{mg}$. Nitrogen adsorption-desorption isotherms were measured at $77 \mathrm{~K}$ with a Micromeritics analyzer (Belsorp Mini). Thermogravimetric analysis (TGA) was performed on a SDT600 apparatus under a heating rate of $\sim 10 \mathrm{~K} \mathrm{~min}^{-1}$ in air. X-Ray photoelectron spectroscopy (XPS) spectrum was measured on a Perkin-Elmer model PHI 5600 XPS system with a resolution of 0.3-0.5 eV from a monochromated aluminium anode X-ray source. The Raman spectrum was obtained using a Witech CRM200 Raman system with $532 \mathrm{~nm}$ excitation laser. Microscopy observations were conducted by a universal research microscope (OLYMPUS, BX51).

\subsection{Electrochemical testing/characterization}

The working electrodes were fabricated by a conventional slurry-coating method. For details, carbon fibers, poly(vinylidene fluoride) (PVDF) binder and Acetylene Black were mixed in a mass ratio of $80: 10: 10$ and dispersed/homogenized in $N$-methyl-2-pyrrolidone (NMP) to form slurries. The homogenous slurry was then pasted onto a $\mathrm{Cu}$ foil (thickness: 10-15 $\mu \mathrm{m}$ ) and dried at $100^{\circ} \mathrm{C}$ for $10 \mathrm{~h}$ under vacuum. The mass loading of fiber products on each current collector was controlled to be $2.5-4.0 \mathrm{mg} \mathrm{cm}^{-2}$. Electrochemical measurements were all performed using CR-2032 coin-type cells within a potential range of $0.005-3 \mathrm{~V}$. The cells were assembled in an Arfilled glove box (MBraun, Unilab; $\mathrm{H}_{2} \mathrm{O}<0.1 \mathrm{ppm}, \mathrm{O}_{2}<0.1 \mathrm{ppm}$ ) using $\mathrm{Li}$ foil as the counter and reference electrode. $1 \mathrm{M} \mathrm{LiPF}_{6}$ dissolved in a $1: 1(\mathrm{v} / \mathrm{v})$ mixture of ethylene carbonate (EC) and diethyl carbonate (DEC) was used as the electrolyte. Electrochemical impedance spectroscopy and cyclic voltammetry measurements were performed on an electrochemical workstation (CHI 760D, CH Instruments Inc., Shanghai) and galvanostatic charge-discharge tests were conducted using a specific battery tester (NEWARE, Shenzhen). Prior to battery testing, all cells were aged for $8 \mathrm{~h}$.

\section{Results and discussions}

\subsection{Characterizations of bamboo chopsticks}

Bamboo usually acts as an all-purpose problem solver and suits a wide range of applications by virtue of its unique fibrous structure. ${ }^{7}$ Bamboo chopsticks made of bamboo culms can be anatomically perceived as an aggregation of numerous oriented cellulose fibers embedded in an interwoven ligneous matrix (see the schematic in Fig. 1A). The tubular cellulose fibers (mass ratio: $\sim 60 \%$ ) have a biological function as nutrient/water transport corridors between the root and the leaves, whereas the part of lignin (mass ratio: $10 \%-20 \%$ ), a sort of 3D highly crosslinked polyphenolic polymer, ${ }^{8}$ plays the role of binding these fibers together. Microscopy observations on bamboo chopsticks are shown in Fig. 1B-D. Closer inspection toward their transverse section reveals that they distribute a large quantity of micro-sized fibers in bamboo, particularly around or near the vascular bundles. Scanning electron microscope (SEM) images
(Fig. 1E-H) also show appealing microstructures of these natural fibers, with a tubular diameter ranging from 5 to $10 \mu \mathrm{m}$. The fibrous structure seems preferable for energy storage applications like supercapacitors and LIBs because the tubular architecture itself can provide large inner surface areas and enrich the electrochemically active sites when compared to the solid counterpart. ${ }^{9}$ Note that on the tubular wall of bamboo fibers there exist plenty of nanosized holes or cavities. These natural nanostructures that originally offer passages for biomass exchange between neighboring fibers are also favorable for energy storage, capable of supplying extra access to the inside of microtubes and thus shorten the distances for ionic diffusion. Nevertheless, it is unfortunate that bamboo fibers always bundle tightly with each other even after high-temperature carbonization or high-energy ball-milling treatments. ${ }^{7}$ Though using techniques of boiling, soaking or mechanical extraction is helpful for the isolation of bamboo fibers, the yielded fiber products are rather rough. ${ }^{10}$ Their diameters are usually centered at $\sim 200 \mu \mathrm{m}$, signifying that at least hundreds of microfibers are still bundled together. Such bulky carbonized host materials are difficult to be completely permeated by the electrolyte. This is not beneficial for kinetic intercalation/deintercalation of $\mathrm{Li}^{+}$. In an effort to tap the full potential of each fiber for LIBs, advanced techniques of fiber extraction/dispersion with good scalability are highly encouraged.

\subsection{Carbon fibers evolved from bamboo chopsticks}

We hereby develop a simple and effective way of evolving bamboo chopsticks into individual carbon fibers to address the fibers extraction/dispersion issue above and to enable each single carbon fiber applicable for Li storage. Fig. 2A displays the entire evolution procedures. Recycled bamboo chopsticks are firstly cleaned and made into shavings followed by a hydrothermal treatment performed in an alkaline solution for lignin removal. During the hydrothermal process, the lignin part between neighboring bamboo fibers gradually dissolves into the hot $\mathrm{KOH}$ solution. The trace for lignin removal/dissolution was captured using SEM observation (see Fig. S1†). We need to stress that the use of $\mathrm{KOH}$ would never be a critical issue for the scale up of our synthetic procedures since such treatments with alkali have been adopted in varieties of industrial productions, especially in paper and printing/dyeing industries. After lignin removal, the cotton-like cellulose fibers mixed with residual $\mathrm{KOH}$ are further calcined at $800{ }^{\circ} \mathrm{C}$ under the protection of $\mathrm{Ar}$ flow. Particularly noteworthy is that our produced carbon fibers still maintain good toughness (no visible changes appear even after a press of 10 pound weight; see Fig. S2†), unlike other fragile fibers made from cotton, silk or cobweb. ${ }^{11}$ SEM and TEM observations (Fig. 2B-E and S3A $\dagger$ ) illustrate the yielded fibrous products are uniformly dispersed, having a fluffy texture and a large aspect ratio of a magnitude of several hundreds or even thousands (the mean diameter of the single fiber is observed no more than $6 \mu \mathrm{m}$ while its maximum length even reaches a few centimeters upward). This special "ultrahigh-aspect-ratio" property would potentially endow the anodic electrode with an outstanding high-rate performance by transferring electrons 

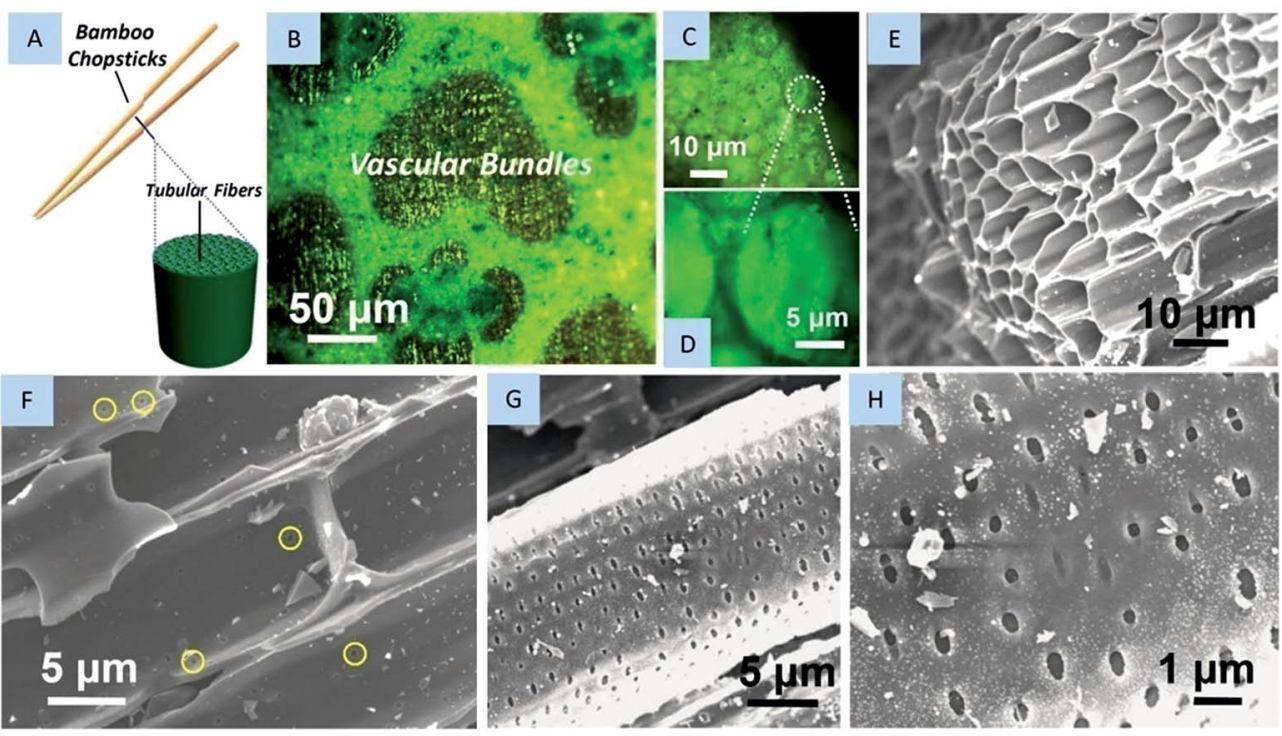

Fig. 1 (A) Basic structures of disposable bamboo chopsticks. (B-D) Microscopy observations on the transverse section of bamboo chopsticks and $(E-H)$ SEM observations toward the inside of oriented fibers.
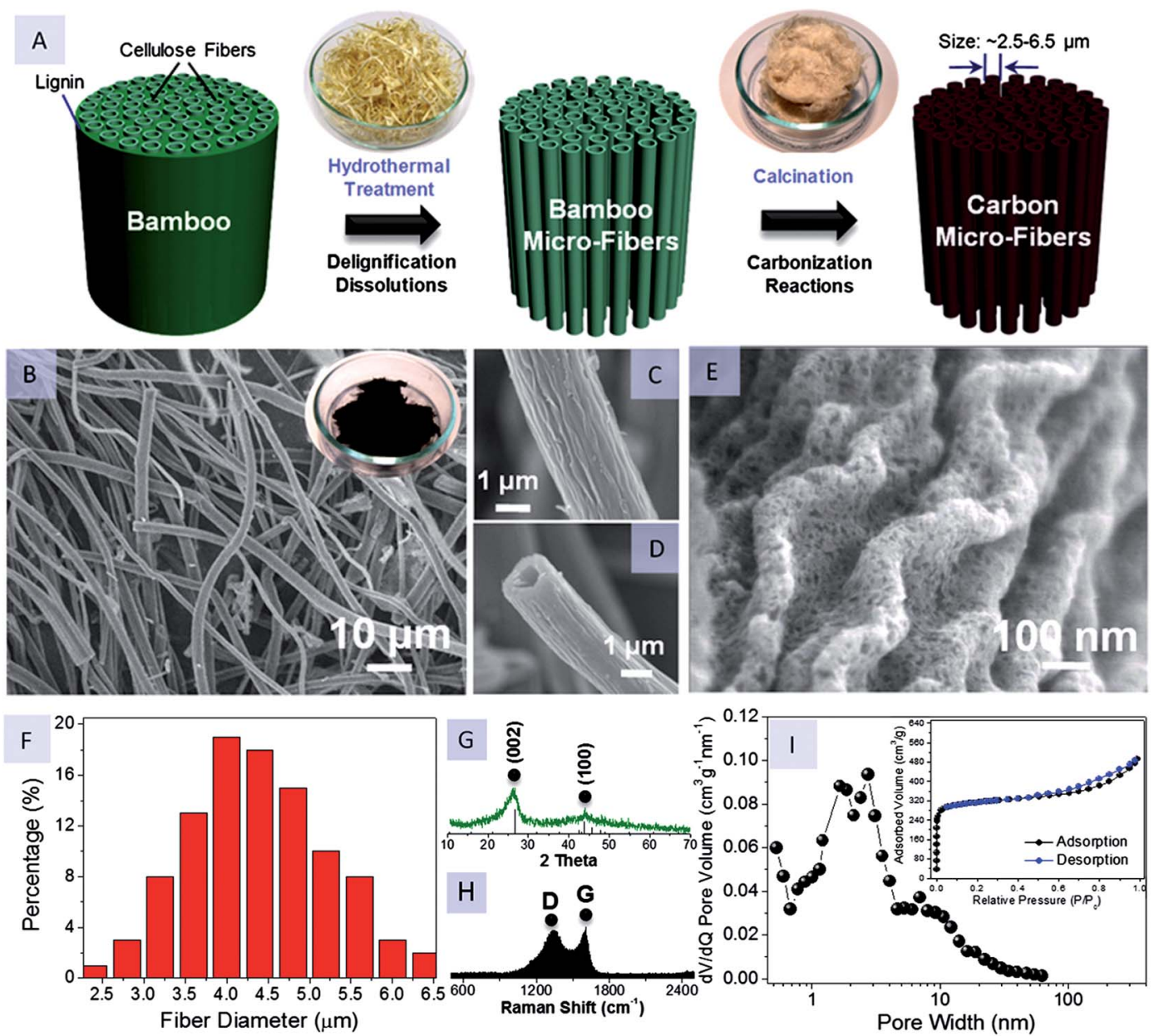

Fig. 2 (A) Schematic diagram displaying the overall evolution of bamboo chopsticks into uniform carbon fibers. (B-E) Optical and SEM images, (F) diameter distribution curve, (G) XRD pattern, (H) Raman spectrum and (I) pore-size distribution curve of produced carbon fibers. The inset in (I) is their $\mathrm{N}_{2}$ adsorption isotherm. 
directly along the long $1 \mathrm{D}$ electronic conducting cables rather than in disordered particle networks through numerous interparticle contacts. ${ }^{\mathbf{1 2}}$ Another structural highlight is that on the carbon fiber surface there are homogeneously distributed mesoporous pores (10-20 $\mathrm{nm}$ in dimensions), which are quite accessible for the deep insertion of $\mathrm{Li}^{+}$into the whole fiber region. The generation of these mesopores results from the activation process by means of alkali $(\mathrm{KOH})$ corrosion to carbon materials at a high temperature $\left(6 \mathrm{KOH}+\mathrm{C} \rightarrow 2 \mathrm{~K}+3 \mathrm{H}_{2}+2\right.$ $\left.\mathrm{K}_{2} \mathrm{CO}_{3}\right) \cdot{ }^{13}$ Fig. $2 \mathrm{~F}$ shows the diameter distribution for a representative set of derived fiber samples. The fiber diameters are mainly varied from 2.4 to $6.4 \mu \mathrm{m}$ with the highest distribution between 3.6 and $4.8 \mu \mathrm{m}$. In optimized states, we find that the minimum thickness of carbon fibers is even down to $\sim 600 \mathrm{~nm}$ (see Fig. S3B and $\mathrm{C}^{\dagger}$ ). All these values are lower than that of pristine fibers $(\sim 10 \mu \mathrm{m})$ in bamboo chopsticks, attributed to the volumetric contraction of cellulose fibers when bamboo chopsticks are successively subjected to delignification and carbonization treatment. The XRD pattern (Fig. 2G) and Raman spectrum (Fig. 2H) are also used to characterize the carbon fibers. The well-defined two diffraction peaks present in the XRD pattern correspond to (002) and (100) facets of hexagonal carbon (JCPDS no. 41-1487), respectively. Both diffraction peaks look broad since the graphite domain/crystalline size is extremely small, though specimens have been annealed at a temperature as high as $800{ }^{\circ} \mathbf{C} .{ }^{5 a}$ According to the Scherrer equation, the mean domain thickness is calculated to be $\sim 1.85$ $\mathrm{nm}$ from the full width at half-maximum values of (002) peak. This suggests that the graphitic domain is composed of 5-6 carbon layers (i.e., 1.85/0.34 $=5.44$ ), matching well the result of HRTEM observation (Fig. S3D $\dagger$ ). The Raman spectrum shows two fingerprint peaks, involving a disorder-induced $\mathrm{D}$ band $\left(1341 \mathrm{~cm}^{-1}\right)$ and an in-plane vibrational $\mathrm{G}$ band $\left(1592 \mathrm{~cm}^{-1}\right)$. The $\mathrm{G}$ band has a bit higher peak intensity than the $\mathrm{D}$ band $\left(I_{\mathrm{D}} /\right.$ $I_{\mathrm{G}}$ ratio is $\sim 0.96$ ), indicative of a higher degree of graphitization than the commercially used carbon cloth, carbon fiber papers or even carbon nanotubes in previous literature sources. ${ }^{\mathbf{1 4}}$ The Xray photoelectron spectroscopy (XPS) measurement on a carbon fiber surface (Fig. S4†) discloses that there remain other elements like $\mathrm{F}(9.5 \%), \mathrm{O}(6.5 \%)$ and $\mathrm{Cl}(1.0 \%)$. The as-formed functional groups (e.g., $\mathrm{C}-\mathrm{O}, \mathrm{C}=\mathrm{O}, \mathrm{C}-\mathrm{F}, \mathrm{C}-\mathrm{Cl}$, etc.) are quite useful since they may contribute part of the capacities via lithiation/delithiation or pseudocapacitive reactions. The $\mathrm{N}_{2}$ adsorption-desorption isotherm with a hysteresis loop (inset in Fig. 2I) shows a typical "type I" characteristics (according to IUPAC recommendations) which is usually displayed by microporous solids especially for instances of carbon materials. ${ }^{15}$ The specific surface area for evolved carbon fibers is measured around $\sim 808.25 \mathrm{~m}^{2} \mathrm{~g}^{-1}$. Also, we have calculated the micropore size of fiber specimens based on the density functional theory (DFT) (Fig. 2I). The carbon fibers contain $\sim 47 \%$ microporosity below $2 \mathrm{~nm}$, with small mesopores centered among a range of $2-10 \mathrm{~nm}$. The existence of such surface defects and hydrophilic function groups as above is very helpful for the nucleation formation of other functionalized active materials on the carbon surface. ${ }^{16}$ This potentially enables the immobilization of high-capacity materials with robust mechanical adhesion to carbon fibers scaffold, eventually forming advanced core-shell synergetic hybrid electrode systems for LIBs. Moreover, we have measured the electrical performance of a single carbon fiber (Fig. S5 $\dagger$ ). Its electrical resistivity is evaluated around $\sim 10^{-1} \Omega \mathrm{cm}$ (very close to that of metals), which is quite favorable for LIBs performance especially for high-rate lithiation/delithiation.

Seeking to control the entire preparation of bamboo fibers, we thereby carry out systematic studies on the relationships between $\mathrm{KOH}$ concentration $\left(C_{\mathrm{KOH}}\right)$ and other significant parameters like the hydrothermal reaction time and the weight losses of the chopsticks. Fig. 3A and B successively display their reaction time $(t)$ and percentage loss in weight (wt\%) as a function of $C_{\mathrm{KOH}}$ at a constant hydrothermal temperature of $150^{\circ}$. When $C_{\mathrm{KOH}}$ is as much as $1 \mathrm{M}, t$ of $15 \pm 2 \mathrm{~h}$ needs to be spent for the complete extraction of bamboo fibers. This treatment gives rise to a wt $\%$ up to $\sim 31.3 \%$. Upon the increase of

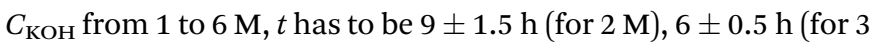
$\mathrm{M}$ ), $5 \pm 0.3 \mathrm{~h}$ (for $4 \mathrm{M}$ ), $4.75 \pm 0.25 \mathrm{~h}$ (for $5 \mathrm{M}$ ) and $4.5 \pm 0.2 \mathrm{~h}$ (for $6 \mathrm{M}$ ), corresponding to the wt\% of $\sim 28.3 \%, \sim 22.7 \%$, $\sim 23.3 \%, \sim 26.7 \%, \sim 33 \%$, respectively. As reflected by the experimental data and their fitting analysis, the fiber-extraction procedure is proven to be highly associated with $t$ and $C_{\mathrm{KOH}}$ parameters. Using a high molar-ratio alkali solution enables to shorten $t$ by acceleration of the delignification process but in turn inevitably causes dissolution of the partial cellulose fibers ( $\sim 21 \%$ solubility percentage in concentrated alkaline) as well as the high $\mathrm{wt} \%{ }^{17}$ Though prolonging the hydrothermal time indeed eliminates the use of concentrated $\mathrm{KOH}$ solution, the corresponding $w \mathrm{t} \%$ is not the lowest since a long hydrothermal period would also result in a partial weight loss of the biomass. Considering the manufacturing cost and production efficiency of bamboo fibers, we eventually choose $3 \mathrm{M} \mathrm{KOH}$ as the hydrothermal solution, along with a moderate $t(6 \mathrm{~h})$ and the lowest wt\% ( 22.7\%). Moreover, we also pay close attention to other influence factors, like reaction conditions, as compared and summarized in Table 1 . Underneath the $5 \mathrm{~h}$ soaking treatment in either alkaline/acid solutions or neutral water, we fail to attain any cellulose fibers; there are actually no changes on bamboo chopsticks after the soaking process except for the ones soaking in alkaline aqueous solutions (with a slight weight loss of $\sim 3-6 \%$ caused by dissolution of the biomass in bamboo). As for events under hydrothermal conditions,
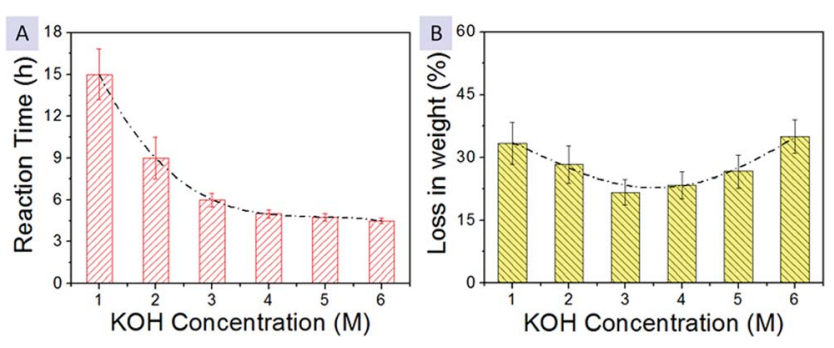

Fig. 3 Relationships between the $\mathrm{KOH}$ concentration $\left(C_{\mathrm{KOH}}\right)$ and other significant parameters of (A) hydrothermal reaction time $(t)$ and (B) weight loss (wt\%) of the chopsticks shavings. 
Table 1 Comparison of bamboo fibers extraction performed by distinct chemical treatments

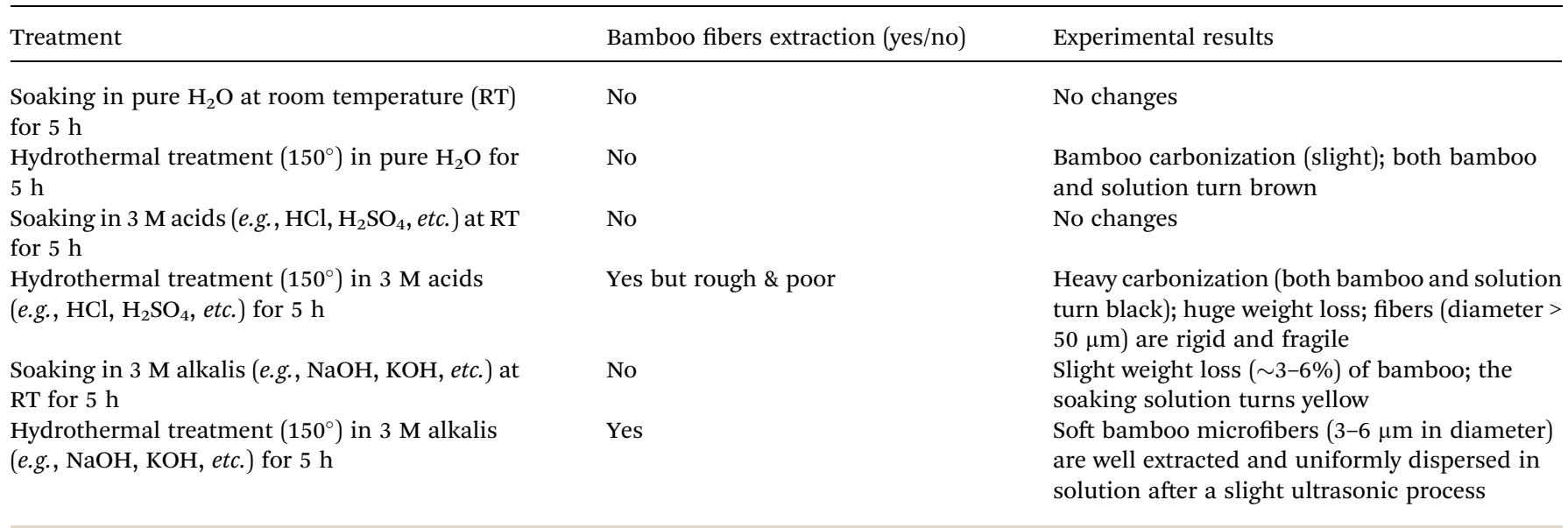

high-quality bamboo fibers $(3-6 \mu \mathrm{m})$ are harvested merely in 3 $\mathrm{M}$ alkalis, instead of in $3 \mathrm{M}$ acids or neutral water (see optical/ SEM observations in Fig. S6†). Even though rough fibers with a mean diameter of $\sim 30 \mu \mathrm{m}$ (marked by arrows in Fig. S6D $\dagger$ ) are also yielded after a hydrothermal process conducted in acids, the as-formed products are substantially carbonized and become rather rigid/fragile, being simultaneously accompanied by remarkable morphological changes (e.g., structural collapse in some regions) and huge weight losses up to $\sim 63 \%$. The resultant carbonization may be induced by complicated intermolecular dehydration, hydrolysis and condensation/polymerization of the organics (like oligosaccharides, hemicelluloses or other molecules in bamboo biomass) in neutral/acid atmosphere when the hydrothermal temperature is held at $150{ }^{\circ} \mathrm{C} .{ }^{18}$

\subsection{Performance of the carbon fibers in LIBs}

LIBs performance of derived carbon fibers was evaluated using coin-type half cells, in which Li metal foils are used as the counter and reference electrode. Cyclic voltammetry (CV) is initially used to examine the charge storage behavior of carbon fibers at a scanning rate of $0.5 \mathrm{mV} \mathrm{s}^{-1}$ over a potential range of $0.005-3.00 \mathrm{~V}$ vs. $\mathrm{Li} / \mathrm{Li}^{+}$(Fig. $4 \mathrm{~A}$ ). In the 1 st $\mathrm{CV}$ scan, there is a cathodic peak present over a wide region attributed to complex phase transitions caused by Li intercalation into carbonaceous fibers. An evident reduction peak emerges at $0.435 \mathrm{~V}$ but disappears in subsequent cycles, which is related to irreversible electrochemical processes like trap of $\mathrm{Li}^{+}$ions in lattices, electrolyte decomposition and formation of solid electrolyte interface (SEI) layer covered on the carbon surface. ${ }^{19}$ The redox reactions of $\mathrm{Li}$ insertion/extraction in the following cycles becomes highly reversible. Li-intercalation reactions take place below $\sim 0.5 \mathrm{~V}$ (the capacity contribution within $\sim 0.5-0.85 \mathrm{~V}$ is ascribed to faradic capacitive reactions on the carbon fiber surface) while the broad anodic peak related to a Li-deintercalation process launches at $\sim 0.28 \mathrm{~V}$, consistent with the cases of carbon species derived from biomass in pioneering works. ${ }^{2 c, 5 a, 12 c}$ The CV curves for the 2nd, 3rd and even 50th cycle nearly overlap with each other, suggesting a highly reversible and electrochemically stable performance of the carbon-fiber electrode.
Galvanostatic charge-discharge tests have been conducted at $\sim 0.37 \mathrm{C}\left(1 \mathrm{C}=372 \mathrm{~mA} \mathrm{~g}^{-1}\right)$ for 800 cycles (Fig. 4B) to estimate the long-term cyclic behavior of carbon fibers. For comparison, unseparated bulky bamboo carbons (see SEM observations in Fig. S7C and $\mathrm{D}^{\dagger}$ ) with an average size of $\sim 100 \mu \mathrm{m}$ are also tested. The electrode of carbon fibers exhibits initial discharge and charge capacities of $\sim 500 \mathrm{~mA} \mathrm{~h} \mathrm{~g}^{-1}$ and $\sim 283 \mathrm{~mA} \mathrm{~h} \mathrm{~g}^{-1}$, respectively. By contrast, the bulk bamboo carbons show a bit higher initial discharge capacity (up to $\sim 535 \mathrm{~mA} \mathrm{~h} \mathrm{~g}{ }^{-1}$ ) but a much lower reversible charge capacity of $\sim 208 \mathrm{~mA} \mathrm{~h} \mathrm{~g}^{-1}$. This implies that carbon fibers possess better reversibility than their bulky counterpart, with an upper initial Coulombic efficiency of $\sim 56.6 \%$. This value is definitely higher than that of bamboo carbons ( $\sim 38.8 \%)$, and even comparable to that of transitional metal oxides. ${ }^{20}$ For carbon fibers, the evident decrease in the irreversible capacity loss during the 1 st cycle may be due to the individual fibrous geometric features; in the kinetics, $\mathrm{Li}^{+}$may not tend to be trapped because carbon fibers, the active host materials have been perfectly isolated and dispersed for the ease of $\mathrm{Li}^{+}$intercalation/deintercalation. Both electrodes show a trivial capacity reduction among the prime 30 cycles and later a capacity rise in subsequent steps. The specific capacity of carbon fibers rises from the bottom capacity of $\sim 256 \mathrm{~mA} \mathrm{~h} \mathrm{~g}^{-1}$ to $\sim 355 \mathrm{~mA} \mathrm{~h} \mathrm{~g}^{-1}$ with a growing rate of $\sim 0.25 \mathrm{~mA} \mathrm{~h} \mathrm{~g}{ }^{-1}$ per cycle and then stabilizes at $\sim 360 \mathrm{~mA} \mathrm{~h}^{-1}$, which is more than the practical capacity of commercial graphite $(\sim 300-330 \mathrm{~mA} \mathrm{~h}$ $\mathrm{g}^{-1}$ ) and the capacity values of other carbon materials..$^{2 c, 3 c, 5 a, 21 a}$ Note that similar activation results have been reported on carbon-/silicon-based materials. ${ }^{21}$ We believe that this capacityrise phenomenon may result from two aspects as follows. Within prime tens of cycles, the capacity of carbon fibers begins to recover from the minimum value. The origin of this activation is mainly attributed to the delayed infiltration of an electrolyte into the carbon fibers. ${ }^{21 c}$ Around 100 cycles later, the repeated $\mathrm{Li}$ insertion/deinsertion process would gradually disrupt carbon fibers preferably at the structural defects. Fibers breaking may lead to more open-up places and accordingly provide more active sites available for $\mathrm{Li}$ storage. Besides, $\mathrm{Li}$ ions can go through such open-up regions and further diffuse a 


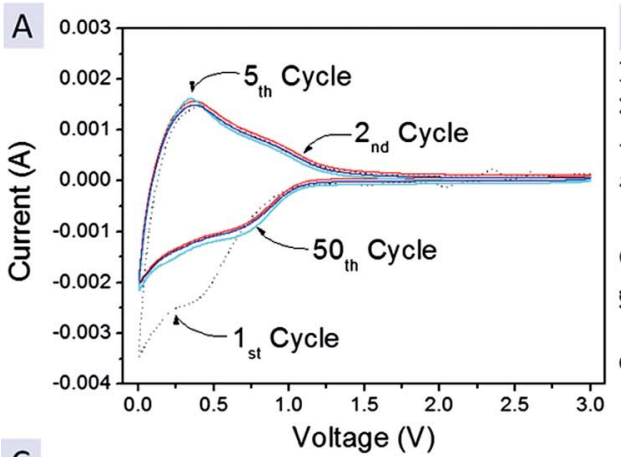

C

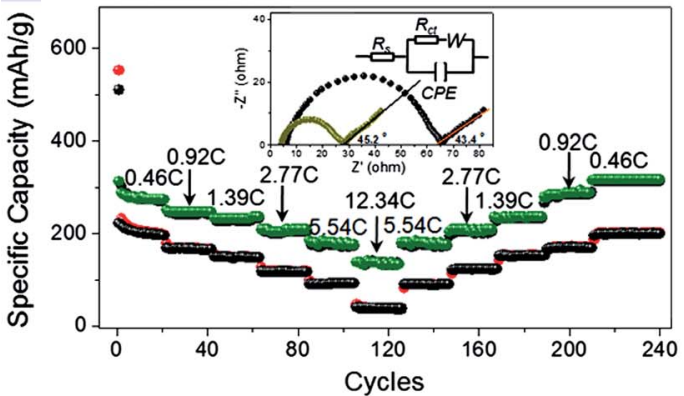

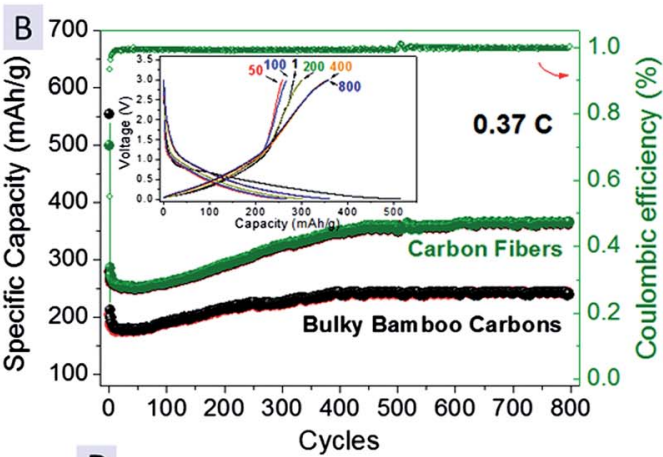

D

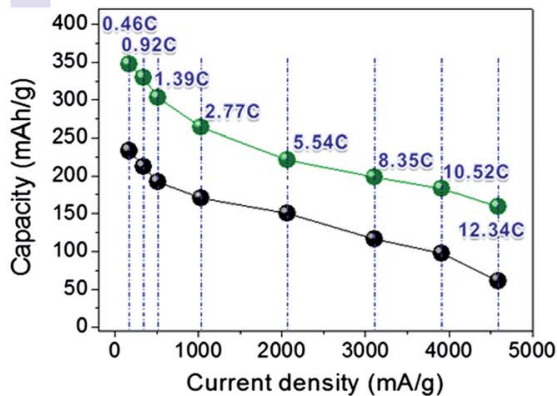

Fig. 4 (A) CV curves of carbon fibers electrode between 0.005 and $3.0 \mathrm{~V}$ at a scanning rate of $0.5 \mathrm{mV} \mathrm{s}^{-1}$. (B) Long-term cyclic performance and charge-discharge profiles, (C) programmed cyclic responses and (D) specific capacity vs. current density plot of carbon fibers (green) and bulky bamboo carbons (black). The inset in (C) shows their EIS spectra measured in a frequency range of $1 \times 10^{6}$ to $0.01 \mathrm{~Hz}$ under open-circuit conditions.

few nanometers deep into carbon fibers, which may lead to a continual capacity rise until the entire carbon fiber has been fully utilized. Despite bulky bamboo carbons also having excellent cycling stability and undergoing a similar capacityincreasing process, the delivered capacity is maintained at a level of $\sim 250 \mathrm{~mA} \mathrm{~h} \mathrm{~g}^{-1}\left(\sim 110 \mathrm{~mA} \mathrm{~h} \mathrm{~g}^{-1}\right.$ less than that of carbon
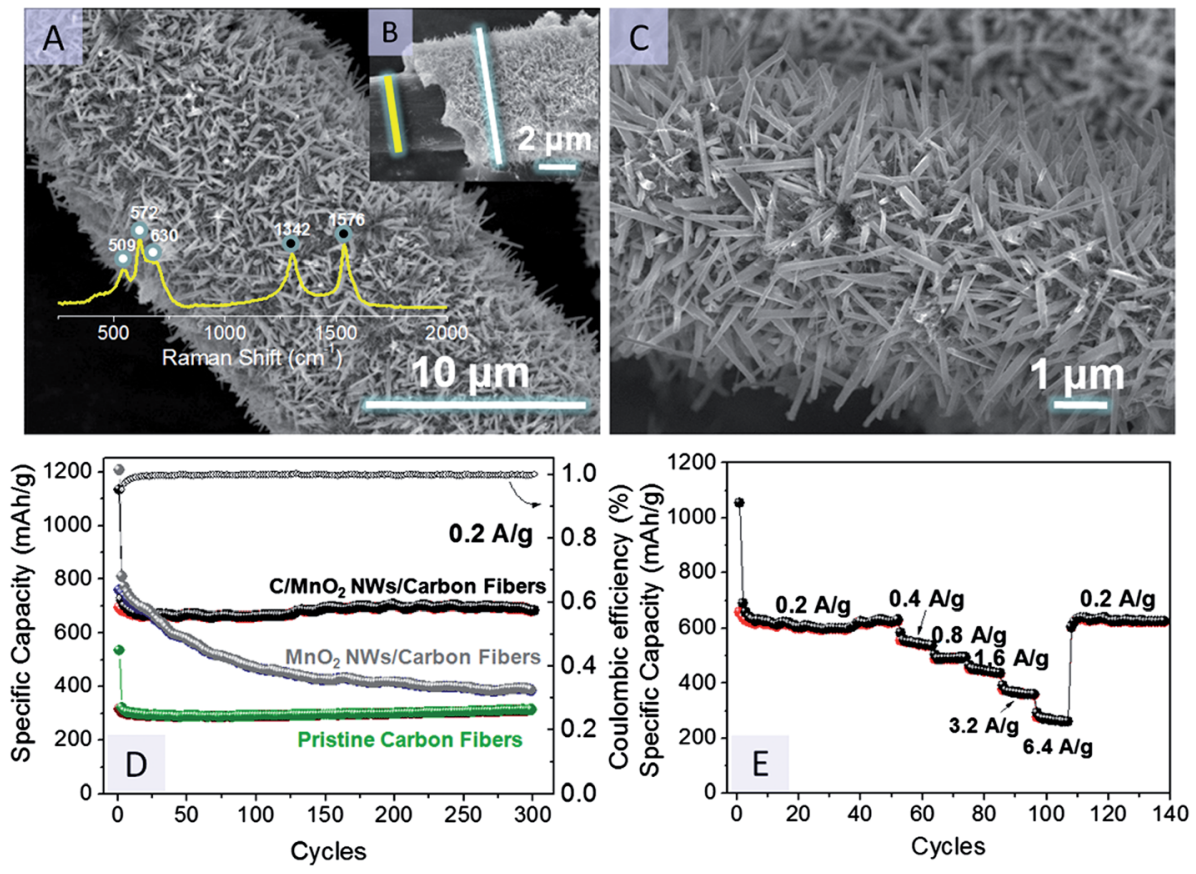

Fig. 5 (A-C) SEM observations toward the $\mathrm{C} / \mathrm{MnO}_{2} \mathrm{NWs} /$ carbon fibers hybrid. The inset in (A) shows the Raman spectrum of this hybrid sample. (D) Cycling performance of $\mathrm{C} / \mathrm{MnO}_{2} \mathrm{NWs} /$ carbon fibers, $\mathrm{MnO}_{2} \mathrm{NWs} /$ carbon fibers and the pristine carbon fibers performed at $\sim 0.2 \mathrm{~A} \mathrm{~g}{ }^{-1}$ for 300 cycles, respectively. (E) Programmed cyclic responses of the $\mathrm{C} / \mathrm{MnO}_{2} \mathrm{NWs} /$ carbon fibers hybrid. 
fibers and far below the practical standard), and the ramped rate is only $\sim 0.15 \mathrm{~mA} \mathrm{~h} \mathrm{~g}{ }^{-1}$ per cycle. Galvanostatic chargedischarge tests at programmed $\mathrm{C}$ rates are further carried out to examine their rate capability (Fig. 4C). The electrode of carbon fibers is primarily subjected to continuous cycling under varied current densities, successively at $0.46 \mathrm{C}\left(171 \mathrm{~mA} \mathrm{~g}^{-1}\right), 0.92 \mathrm{C}$ $\left(342 \mathrm{~mA} \mathrm{~g}^{-1}\right), 1.39 \mathrm{C}\left(517 \mathrm{~mA} \mathrm{~g}^{-1}\right), 2.77 \mathrm{C}\left(1030 \mathrm{~mA} \mathrm{~g}^{-1}\right), 5.54 \mathrm{C}$ $\left(2060 \mathrm{~mA} \mathrm{~g}^{-1}\right)$ and $12.34 \mathrm{C}\left(4590 \mathrm{~mA} \mathrm{~g}^{-1}\right)$ followed by chargedischarge cycles with currents switching back to $0.46 \mathrm{C}$. The corresponding records on the relationship between the reversible capacity and the current density have been summarized in Fig. 4D. The capacity of a carbon fiber electrode can fully recover or even surpass its former values upon continuously switching the current rates, capable of delivering a maximum capacity up to $353 \mathrm{~mA} \mathrm{~h} \mathrm{~g}^{-1}$ (at $0.46 \mathrm{C}$ ), $319 \mathrm{~mA} \mathrm{~h} \mathrm{~g}^{-1}$ (at $0.92 \mathrm{C}$ ), $292 \mathrm{~mA} \mathrm{~h}$ $\mathrm{g}^{-1}$ (at $1.39 \mathrm{C}$ ), $254 \mathrm{~mA} \mathrm{~h} \mathrm{~g}^{-1}$ (at $2.77 \mathrm{C}$ ) and $211 \mathrm{~mA} \mathrm{~h} \mathrm{~g}^{-1}$ (at $5.54 \mathrm{C}$ ), respectively. All these values are higher than those of bamboo carbons. Note that when the current suddenly jumps to 12.34 $\mathrm{C}$ (4590 $\mathrm{mA} \mathrm{g}^{-1}$; cells charged-discharged in less than 1 min), the electrode of carbon fibers still retains a capacity of $\sim 137 \mathrm{~mA} \mathrm{~h} \mathrm{~g}^{-1}$, which is definitely beyond the value of bamboo carbons $\left(\sim 59 \mathrm{~mA} \mathrm{~h} \mathrm{~g}^{-1}\right)$ and other hard carbon materials; ${ }^{2 c}$ more strikingly, this value is even a bit higher than that of highly conductive carbon nanotubes (CNTs) measured at $10 \mathrm{C}$ (3720 $\left.\mathrm{mA} \mathrm{g}^{-1}\right){ }^{3 c}$ The above results highlight both the excellent rate capability and capacity retention of derived carbon fibers, showing a great promise to function as an alternative anodic substitute for graphite in LIBs. Electrochemical impedance spectroscopy (EIS) recorded in the frequency range of $1 \times 10^{6}$ to $0.01 \mathrm{~Hz}$ under open-circuit conditions is shown in the inset of Fig. 4C. The data fitted from the semicircle in high frequency range reveal the electrode of carbon fibers has a low chargetransfer resistance $\left(R_{\mathrm{ct}}\right)$ of $\sim 24 \Omega$ (substantially lower than that of bulky bamboo carbons $(\sim 61 \Omega)$ ), evidencing the individual carbon fibers possess better electrolyte infiltration and chargetransport capability than the bulk. In the low frequency range, a comparison toward the fitting line slope illustrates carbon fibers electrode exhibits less Warburg impedance $\left(Z_{\mathrm{w}}\right)$, which represents a significant parameter associated with the diffusion of $\mathrm{Li}^{+}$ions along the inter-space of graphitic carbons. ${ }^{22}$ The above impedance spectra suggest the electrode of carbon fibers undergoes a fast Faradaic process and has a lower activation energy for $\mathrm{Li}^{+}$diffusion into graphitic lattices. Even after deep cycling, the $R_{\text {ct }}$ of carbon fibers does not change a lot (Fig. S8 $\dagger$ ). Apart from the electrochemical testing/analysis, we also compare the cost of anodic materials made from chopsticksderived carbon fibers with the commercially used graphite (see Table $\mathbf{S 1 \dagger}$ ). The unit prices given out are all referenced in the recent literature ${ }^{5 a}$ and the global trade website http:// Alibaba.com. Assuming each coin-type cell contains $\sim 100 \mathrm{mg}$ active anode materials, the use of carbon fibers would bring about around \$30-41 for manufacturing 10000 cells in lab. The total amount is lower than that of graphite (\$39-54), implying the cost advantage of evolved carbon fibers for LIBs industry.

Though carbon fibers are proven superior to bulky bamboo carbons and competent in sustainability, the battery performance and cost (raw materials are renewable and all recycled from wastes) with graphite (a type of limited fossil/mineral resource), their energy density is yet problematic to meet the ever-growing demand for modern energy-storage applications. Aimed to upgrade their energy density, we have tried various strategies to optimize carbon fibers, either by growth of functionalized metal oxides on each fiber scaffold or doping active elements (like B, N, F and $\mathrm{P}$ etc.) on/into the fibrous carbon host. ${ }^{23-25}$ One model example is the promotion of the anodic performance by constructing carbon-coated $\mathrm{MnO}_{2}$ nanowires (NWs) on the carbon fibers, forming a smart sandwich-like hybrid (denoted as $\mathrm{C} / \mathrm{MnO}_{2} \mathrm{NWs} /$ carbon fibers). The choice of $\mathrm{MnO}_{2}$ as an incorporated electrode material is mainly given by factors like manufacturing complexity, environment friendliness, cost and natural abundance. Another notable reason is that unlike other transition metal oxides with conversion reactions occurring above $\sim 1 \mathrm{~V},{ }^{14 a, 18 c, 24} \mathrm{MnO}_{2}$ has a low lithiation plateau of $\sim 0.5 \mathrm{~V} v s$. $\mathrm{Li} / \mathrm{Li}^{+}$(approaching the value of carbon species). This is definitely below the lowest unoccupied molecular orbital (LUMO) of liquid organic electrolyte but still keeps higher than the Li-reduction potential, enabling generation of stable protective passivation layers on the anode surface to ensure cyclic durability and simultaneously avoiding a yield of detrimental Li dendrites for safety. ${ }^{4}$ An XRD measurement has clearly identified the formation of $\mathrm{C} / \mathrm{MnO}_{2} \mathrm{NWs} /$ carbon fibers hybrid after a series of post-treatments (see Fig. S9A $\dagger$ ). Fig. 5A-C show representative SEM images of $\mathrm{C} / \mathrm{MnO}_{2} \mathrm{NWs} /$ carbon fibers hybrid products. The samples geometrically inherit the fibrous features and possess intriguing hierarchical structures consisting of a carbon fiber inner core and $\mathrm{MnO}_{2}$ NWs outer shells. According to the above XRD record and the HRTEM observation (Fig. S9B $\dagger$ ), the produced oxide is identified as $\alpha$-type $\mathrm{MnO}_{2}$ within a space group of $I 4 / \mathrm{m}$. In addition to being immobilized as a robust shell (shell thickness: $3-5 \mu \mathrm{m}$ ) on each carbon fiber surface, a uniform carbon layer with fewnanometer thickness is intimately coated on $\mathrm{MnO}_{2} \mathrm{NWs}$, as confirmed a by high-resolution TEM observation (Fig. S9C, $\dagger$ see arrows) and Raman spectrum (inset in Fig. 5B; Raman peaks at 505,572 and $630 \mathrm{~cm}^{-1}$ corresponds to distinct $\mathrm{Mn}-\mathrm{O}$ stretching modes of $\mathrm{MnO}_{2}$ while the ones located at 1342 and $1576 \mathrm{~cm}^{-1}$ are fingerprints for the thin carbon layer). As a consequence, nanostructured $\mathrm{MnO}_{2}$ with a high theoretical capacity of $\sim 1230$ $\mathrm{mA} \mathrm{h} \mathrm{g}^{-1}$ has been perfectly encapsulated into a carbon matrix (by referring to the thermogravimetric analysis (TGA) in Fig. $\mathrm{S} 10 \mathrm{~B}, \dagger$ the mass ratio of $\mathrm{MnO}_{2}$ in $\mathrm{C} / \mathrm{MnO}_{2} \mathrm{NWs} /$ carbon fibers is determined to be $\sim 45.7 \%$ ). Such designed electrode architecture is quite favorable for LIBs application, alleviating the problems led by self-aggregation and intrinsically low electronic conductivity of $\mathrm{MnO}_{2}$, as well as the lithiation-induced stresses. As a proof-of-concept demonstration of such hybrid products in LIBs, we have evaluated the hybrid of $\mathrm{C} / \mathrm{MnO}_{2} \mathrm{NWs} /$ carbon fibers (CV and charge-discharge curves are successively present in Fig. S10C and $\mathrm{D} \dagger$ ). Also, we compare the cyclic behavior of $\mathrm{MnO}_{2} /$ carbon fibers (without carbon coating) and pristine carbon fibers. Fig. 5D displays their cyclic performance at $0.2 \mathrm{~A} \mathrm{~g}^{-1}$ in a potential range of $0.005-3 \mathrm{~V} \cdot \mathrm{C} / \mathrm{MnO}_{2} \mathrm{NWs} /$ carbon fibers hybrid electrode delivers initial discharge-charge capacities of $1105 \mathrm{~mA} \mathrm{~h} \mathrm{~g}^{-1}$ and $706 \mathrm{~mA} \mathrm{~h} \mathrm{~g}^{-1}$, respectively. The 
capacity loss can be attributed to: (i) irreversible intercalation of $\mathrm{Li}^{+}$into carbon fibers, (ii) irreversible conversion of $\mathrm{MnO}_{2}$ with $\mathrm{Li}^{+}$, and (iii) the formation of SEI film on electrode surfaces. The reversibe discharge capacity after 300 cycles is still kept at $\sim 710 \mathrm{~mA} \mathrm{~h} \mathrm{~g}^{-1}$ (nearly two times that of pristine carbon fibers and far higher than that of $\mathrm{MnO}_{2} /$ carbon fibers electrode), showing $93.8 \%$ retention of the 2 nd discharge capacity. Fig. $5 \mathrm{E}$ shows the programmed cyclic responses of the hybrid products at varied current densities. Along with the increase of current rates from 0.2 to $6 \mathrm{~A} \mathrm{~g}^{-1}$, the electrode of $\mathrm{C} / \mathrm{MnO}_{2} \mathrm{NWs} /$ carbon fibers still exhibits stabilized cyclic behavior, with maximum discharge capacities of 706, 578, 532, 478, 398 and $241 \mathrm{~mA} \mathrm{~h} \mathrm{~g}^{-1}$ at $0.2,0.4,0.8,1.6,3.2$ and $6.4 \mathrm{Ag}^{-1}$, respectively. Even when the current abruptly jumps back to $0.2 \mathrm{~A} \mathrm{~g}^{-1}$, the electrode is even able to deliver a higher reversible capacity of $\sim 715 \mathrm{~mA} \mathrm{~h} \mathrm{~g}^{-1}$. These results exclusively confirm the enhanced energy-storage and rate capabilities of $\mathrm{C} / \mathrm{MnO}_{2} \mathrm{NWs} /$ carbon fibers hybrids over the pristine carbon fibers and the single-phased $\mathrm{MnO}_{2}$ anode. ${ }^{26}$ The high capacity retention and outstanding rate behavior are mainly ascribed to the synergy effects between $\mathrm{MnO}_{2}$ and the carbon matrix. On one hand, nanostructured $\mathrm{MnO}_{2}$ with a large surface to volume ratio ensures the delivery of a high specific capacity for the hybrid electrode of $\mathrm{C} / \mathrm{MnO}_{2} \mathrm{NWs} /$ carbon fibers. On the other hand, the inner carbon fibers backbone functions as the robust scaffold and electric cables for electrons transfer, whereas the uniform carbon layers on the outer surface of $\mathrm{MnO}_{2}$ NWs are responsible for positive mechanical protections.

\section{Conclusions}

In summary, a facile and scalable approach was developed to transform the bamboo chopsticks waste into carbon fibers for LIBs application. The recycled bamboo chopsticks are merely subjected to a simple and controllable delignification process conducted in alkaline aqueous solutions. The natural cellulose fibers in bamboo can then be separated and dispersed automatically. It is confirmed that the reaction time and alkali concentration are both key parameters for controlling the whole fibre extraction process. The obtained natural fibers are further evolved into graphitic carbon fibers after carbonization treatment. When evaluated as anode of LIBs, the derived carbon fibre products show a comparable anodic performance to practical graphitic materials, and far better electrochemical behavior than unseparated bulky bamboo carbons in specific energy and high-rate capabilities. The electrode performance of carbon fibers can be optimized by growing nanostructured metal oxides (typically like $\mathrm{MnO}_{2}$ ) robustly on a carbon fiber surface, leading to the formation of an appealing 3D synergetic core-shell electrode architecture. The as-designed hybrid electrode of $\mathrm{C} / \mathrm{MnO}_{2} \mathrm{NWs} /$ carbon fibers has been verified as an excellent anode material for LIBs, with good cycling performance ( $\sim 710 \mathrm{~mA} \mathrm{~h} \mathrm{~g}^{-1}$ without decay lasting 300 cycles) and excellent rate performance. The enhanced electrochemical performance is ascribed to the combination of carbon fibers, robust backbone and conducting cable, and $\mathrm{C} / \mathrm{MnO}_{2} \mathrm{NWs}$ firmly anchored to the carbon fibers surface, forming a uniqiue core-shell electrode architecture with great synergetic effects.
This work provides a facile and effective way to evolve bamboo chopsticks waste into useful carbon fibers, and more importantly supplies a sustainable and cost-effective platform to develop advanced carbon-based materials for practical use, not merely in LIBs but also in other fields like biosensors, wave absorption, etc.

\section{Acknowledgements}

This work is supported by the Singapore National Research Foundation under NRF-RF award no. NRF-RF2010-07, A*Star SERC PSF grant 1321202101 and MOE Tier 2 MOE2012-T2-2049. H.Z. thanks for support from MOE under AcRF Tier 2 (ARC 26/13, no. MOE2013-T2-1-034), AcRF Tier 1 (RG 61/12, RGT18/ 13, RG5/13), and Start-Up Grant (M4080865.070.706022) in Singapore. This research is also conducted by NTU-HUJ-BGU Nanomaterials for Energy and Water Management Programme under the Campus for Research Excellence and Technological Enterprise (CREATE), which is supported by the National Research Foundation, Prime Minister's Office, Singapore. The authors thank Prof. Sum Tze Chien at Nanyang Technological University for XPS testing.

\section{References}

1 (a) P. G. Bruce, B. Scrosati and J.-M. Tarascon, Angew. Chem., Int. Ed., 2008, 47, 2930; (b) J.-M. Tarascon and M. Armand, Nature, 2001, 414, 359.

2 (a) B. Kang and G. Ceder, Nature, 2009, 458, 190; (b) B. L. Ellis, K. T. Lee and L. F. Nazar, Chem. Mater., 2010, 22, 691; (c) V. G. Pol and M. M. Thackeray, Energy Environ. Sci., 2011, 4, 1904.

3 (a) H. Li, Z. Wang, L. Chen and X. Huang, Adv. Mater., 2009, 21, 4593; (b) Y. Zhu, S. Murali, W. Cai, X. Li, J. Suk, J. R. Potts and R. S. Ruoff, Adv. Mater., 2010, 23, 3906; (c) H. Zhang, G. Cao and Y. Yang, Energy Environ. Sci., 2009, 2, 932; (d) L. Li, A. O. Raji and J. M. Tour, Adv. Mater., 2013, 25, 6298.

4 J. B. Goodenough, Energy Environ. Sci., 2014, 7, 14.

5 (a) W. E. Tenhaeff, O. Rios, K. More and M. A. McGuire, $A d v$. Funct. Mater., 2014, 24, 86; (b) J. Ding, H. Wang, Z. Li, A. Kohandehghan, K. Cui, Z. Xu, B. Zahiri, X. Tan, E. M. Lotfabad, B. C. Olsen and D. Mitlin, ACS Nano, 2013, 7, 11004; (c) D. S. Jung, M.-H. Ryou, Y. J. Sung, S. B. Park and J. W. Choi, Proc. Natl. Acad. Sci. U. S. A., 2013, DOI: 10.1073/pnas.1305025110.

6 (a) H. Dayle and L. Rachel, Food and Nutrition, Marshall Cavendish Reference, New York, USA, 2009, p. 1043; (b) Asia Times Online, Rising Chinese chopstick prices help Japan firm, accessed September, 2011, http:// www.atimes.com/atimes/China_Business/HD20Cb01.html.

7 (a) H. P. Khalil, I. Bhat, M. Jawaid, A. Zaidon, D. Hermawan and Y. S. Hadi, Mater. Des., 2012, 42, 353; (b) S. Jain, R. Kumar and U. Jindal, J. Mater. Sci., 1992, 27, 4598; (c) L. Osorio, E. Trujillo, A. Van Vuure and I. Verpoest, J. Reinf. Plast. Compos., 2011, 30, 396. 
8 (a) R. K. Sharma, J. B. Wooten, V. L. Baliga, X. Lin, W. G. Chan and M. R. Hajaligo, Fuel, 2004, 83, 1469; (b) H. Nimz, Angew. Chem., Int. Ed., 1974, 13, 313.

9 J. Jiang, Y. Li, J. Liu, X. Huang, C. Yuan and X. W. Lou, Adv. Mater., 2012, 24, 5166.

10 (a) M. Das and D. Chakraborty, J. Appl. Polym. Sci., 2008, 107, 522; (b) A. P. Deshpande, M. Bhaskarrao and C. L. Rao, J. Appl. Polym. Sci., 2000, 76, 83.

11 (a) F. Omenetto and D. Kaplan, Science, 2010, 329, 528; (b) F. Vollrath and D. Porter, Soft Matter, 2006, 2, 377.

12 (a) S. Ding, J. Chen and X. W. Lou, Adv. Funct. Mater., 2011, 21, 4120; (b) J. Jiang, Y. Li, J. Liu and X. Huang, Nanoscale, 2011, 3, 45; (c) J. Chen, J. Z. Wang, A. I. Minett, Y. Liu, C. Lynam, H. Liu and G. G. Wallace, Energy Environ. Sci., 2009, 2, 393.

13 (a) Y. Zhu, S. Murali, M. Stoller, K. Ganesh, W. Cai, P. Ferreira, A. Pirkle, R. Wallace, K. A. Cychosz, M. Thommes, D. Su, E. A. Stach and R. S. Ruoff, Science, 2011, 332, 1537; (b) Y. J. Kim, B. J. Lee, H. Suezaki, T. Chino, Y. Abe, T. Yanagiura, K. C. Park and M. Endo, Carbon, 2006, 44, 1592.

14 (a) Y. S. Luo, J. S. Luo, J. Jang, W. W. Zhou, H. P. Yang, X. Y. Qi, H. Zhang, H. J. Fan, D. Y. Yu, C. M. Li and T. Yu, Energy Environ. Sci., 2012, 5, 6559; (b) J. Jiang, J. Liu, W. W. Zhou, J. H. Zhu, X. T. Huang, X. Y. Qi, H. Zhang and T. Yu, Energy Environ. Sci., 2011, 4, 5000; (c) Y. Luo, J. Jiang, W. Zhou, H. Yang, J. Luo, X. Qi, H. Zhang, D. Yu, C. M. Li and T. Yu, J. Mater. Chem., 2012, 22, 8634.

15 K. Sing, D. Everett, R. Haul, L. Moscou, R. Pierotti, J. Rouquérol and T. Siemieniewska, Pure Appl. Chem., 1985, $57,603$.

16 (a) J. J. Xu, K. Wang, S. Z. Zu, B. H. Han and Z. X. Wei, ACS Nano, 2010, 4, 5019; (b) J. Jiang, J. Liu, R. M. Ding, J. H. Zhu, Y. Y. Li, A. Z. Hu, X. Li and X. T. Huang, ACS Appl. Mater. Interfaces, 2011, 3, 99.

17 J. Cai and L. Zhang, Macromol. Biosci., 2005, 5, 539.

18 (a) H. Wang, Z. Xu, A. Kohandehghan, Z. Li, K. Cui, X. Tan, T. Stephenson, C. K. King'ondu, C. M. B. Holt, B. C. Olsen, J. Tak, D. Harfield, A. O. Anyia and D. Mitlin, ACS Nano, 2013, 7, 5131; (b) X. Sun and Y. Li, Angew. Chem., Int. Ed., 2004, 43, 597.

19 (a) B. Wang, J. S. Chen, H. B. Wu, Z. Y. Wang and X. W. Lou, J. Am. Chem. Soc., 2011, 133, 17146; (b) X. W. Lou, D. Deng, J. Y. Lee and L. A. Archer, Chem. Mater., 2008, 20, 6562; (c) J. Jiang, J. Luo, J. Zhu, X. Huang, J. Liu and T. Yu, Nanoscale, 2013, 5, 8105.
20 (a) J. P. Liu, Y. Y. Li, X. T. Huang, G. Y. Li and Z. K. Li, Adv. Funct. Mater., 2008, 18, 1448; (b) J. Liu, Y. Li, R. Ding, J. Jiang, Y. Hu, X. Ji, Q. Chi, Z. Zhu and X. T. Huang, J. Phys. Chem. C, 2009, 113, 5336; (c) W. W. Zhou, C. W. Cheng, J. Liu, Y. Y. Tay, J. Jiang, X. T. Jia, J. X. Zhang, H. Gong, H. H. Hng, T. Yu and H. J. Fan, Adv. Funct. Mater., 2011, 21, 2439.

21 (a) C. Masarapu, V. Subramanian, H. Zhu and B. Wei, Adv. Funct. Mater., 2009, 19, 1008; (b) H. L. Wang, Z. W. Xu, Z. Li, K. Cui, J. Ding, A. Kohandehghan, X. H. Tan, B. Zahiri, B. C. Olsen, C. M. B. Holt and D. Mitlin, Nano Lett., 2014, 14, 1987; (c) H. Wu, G. Yu, L. Pan, N. Liu, M. T. McDowell, Z. Bao and Y. Cui, Nat. Commun., 2013, 4, 1943.

22 (a) T. Abe, H. Fukuda, Y. Iriyama and Z. Ogumi, J. Electrochem. Soc., 2004, 151, A1120; (b) Y. C. Chang, J. H. Jong and G. T. K. Fey, J. Electrochem. Soc., 2000, 147, 2033.

23 (a) J. Luo, J. Liu, Z. Zeng, C. F. Ng, L. Ma, H. Zhang, J. Lin, Z. Shen and H. J. Fan, Nano Lett., 2013, 13, 6136; (b) B. Liu, J. Zhang, X. Wang, G. Chen, D. Chen, C. Zhou and G. Z. Shen, Nano Lett., 2012, 12, 3005; (c) W. Li, X. Wang, B. Liu, S. Luo, Z. Liu, X. Hou, Q. Xiang, D. Chen and G. Z. Shen, Chem.-Eur. J., 2013, 19, 8650; (d) Q. Xiong, J. P. Tu, X. Xia, X. Zhao, C. Gu and X. L. Wang, Nanoscale, 2013, 5, 7906.

24 (a) Z. Wu, W. Ren, L. Xu, F. Li and H. Cheng, ACS Nano, 2011, 5, 5463; (b) H. Wang, C. Zhang, Z. Liu, L. Wang, P. Han, H. Xu, K. Zhang, S. Dong, J. Yao and G. Cui, J. Mater. Chem., 2011, 21, 5430; (c) Z. Li, Z. Xu, X. Tan, H. Wang, C. M. B. Holt, T. Stephenson, B. C. Olsen and D. Mitlin, Energy Environ. Sci., 2013, 6, 871.

25 (a) N. Du, H. Zhang, B. Chen, J. Wu, X. Ma, Z. Liu, Y. Zhang, D. Yang, X. Huang and J. Tu, Adv. Mater., 2007, 19, 4505; (b) J. Lin, A. O. Raji, K. Nan, Z. Peng, Z. Yan, E. L. G. Samuel, D. Natelson and J. M. Tour, Adv. Funct. Mater., 2014, 24, 2044; (c) W. Zhou, Y. Tay, X. Jia, D. Wai, J. Jiang, H. Hoon and T. Yu, Nanoscale, 2012, 4, 4459; (d) J. Jiang, J. Zhu, R. Ding, Y. Li, F. Wu, J. Liu and X. Huang, J. Mater. Chem., 2011, 21, 15969.

26 (a) A. Reddy, M. M. Shaijumon, S. R. Gowda and P. M. Ajayan, Nano Lett., 2009, 9, 1002; (b) H. Xia, M. Lai and L. Lu, J. Mater. Chem., 2010, 20, 6896; (c) J. Jiang, J. Zhu, Y. Feng, J. Liu and X. Huang, Chem. Commun., 2012, 48, 7471; (d) X. Li, D. Li, L. Qiao, X. Wang, X. Sun, P. Wang and D. He, J. Mater. Chem., 2012, 22, 9189. 